\title{
ENTRAPMENT OF AFTER COMING HEAD IN BICORNUATE UTERUS DURING CESAREAN BREECH DELIVERY OF TERM FETUS
}

Vijayalakshmi B ${ }^{1}$, Amulya M. N²

\section{HOW TO CITE THIS ARTICLE:}

Vijayalakshmi B, Amulya M. N. "Entrapment of After Coming Head in Bicornuate Uterus during Cesarean Breech Delivery of Term Fetus". Journal of Evolution of Medical and Dental Sciences 2015; Vol. 4, Issue 61, July 30; Page: 10738-10741, DOI: $10.14260 /$ jemds/2015/1550

ABSTRACT: INTRODUCTION: The incidence of breech presentation in about 3\% in singleton term pregnancies and about $20 \%$ in preterm pregnancies. The predisposing factors for breech presentation include uterine distension (Polyhydramnios, Multiple gestation), lax uterus (Grand multiparty), uterine anomalies, pelvic tumors, fetal abnormalities (Anencephaly, hydrocephalus, low birth weight), previous breech, placenta previa. Breech presentation increases the risk of morbidity and mortality in both fetus and mother. Nowadays majority of breech deliveries are by caesarian section compared with vaginal delivery. Caesarian section can significantly reduce neonatal complications, with a trivial increase in maternal complications. However caesarian section cannot alleviate all the complications. Hereby we present a case with entrapment of after coming head in caesarian breech delivery of a term fetus. According to current clinical practice in 2001 the American college of obstetricians and gynecologists (ACOG) recommended that "Patient with a persistent breech presentation at term in a singleton gestation should undergo a planned caesarian delivery". Nevertheless it stated that "A planned caesarian delivery does not apply to patients presenting in advanced labour with a fetus in breech presentation in whom deliveries likely to be imminent or in patients where $2^{\text {nd }}$ twin is non-vertex position". ${ }^{1}$

KEYWORDS: Breech Presentation, Bicornuate Uterus, Entrapment of after coming head, Caesarian section.

CASE REPORT: G2P1L0D1 with term gestation with breech presentation in active phase of labour reported to our hospital at $4 \mathrm{pm}$. Her $1^{\text {st }}$ pregnancy was preterm delivery 2 yrs. back at home. Baby died 6 hrs after birth.

0/E: PR-88bpm, BP-110/70mmhg, afebrile. Per abdominally uterus term size with breech in lower pole, head in upper pole, FHS- $132 \mathrm{bpm}$. Per vaginally cervical os $3-4 \mathrm{~cm}$ dilated, $50-70 \%$ effaced, breech at -2 station, membranes absent.

Her investigations revealed $\mathrm{Hb}-9.2 \mathrm{gm} / \mathrm{dl}$, blood group- $\mathrm{AB}$ positive, HIV- non reactive, HBsAgnegative. She was posted for emergency cesarean section.

Intra operatively - a breech was extracted up to nape of neck and there was difficulty for extraction of head. So a vertical incision was taken from upper flap and baby was extracted weighing $2.5 \mathrm{~kg}$ which cried immediately. Placenta delivered, uterus exteriorized, then bicornuate uterus noted which the cause for entrapment of after coming head was.

A vertical incision which was taken was extending into right horn of uterus. Vertical incision sutured in 2 layers followed by transverse incision. Complete hemostasis achieved and abdomen closed in layers. Post-operative period uneventful. Patient discharged on $8^{\text {th }}$ post-operative day after removing sutures. 


\section{CASE REPORT}

This uterine anomaly may be cause for preterm delivery in previous pregnancy.

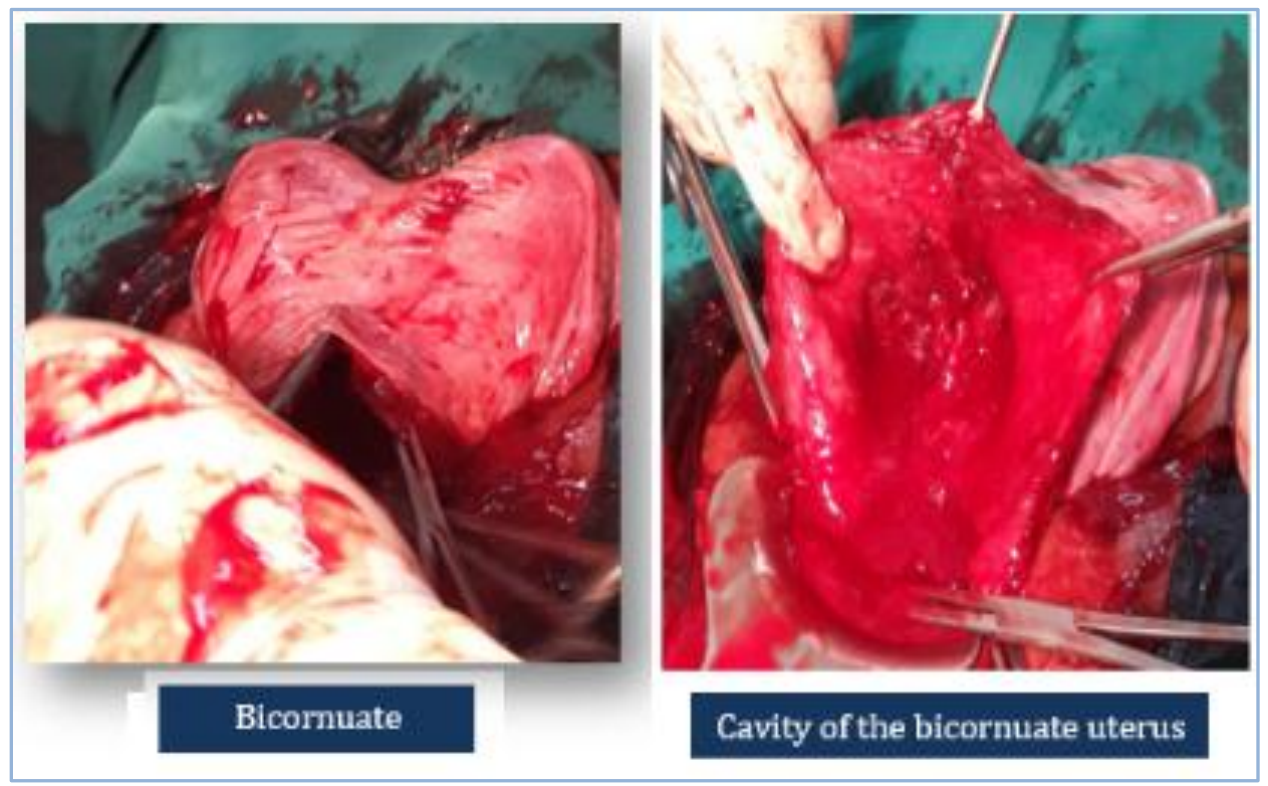

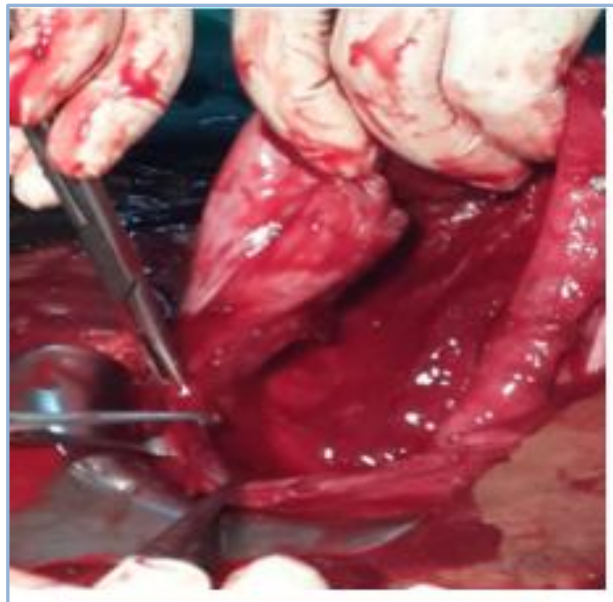

Vertical incision which is extended to right horn

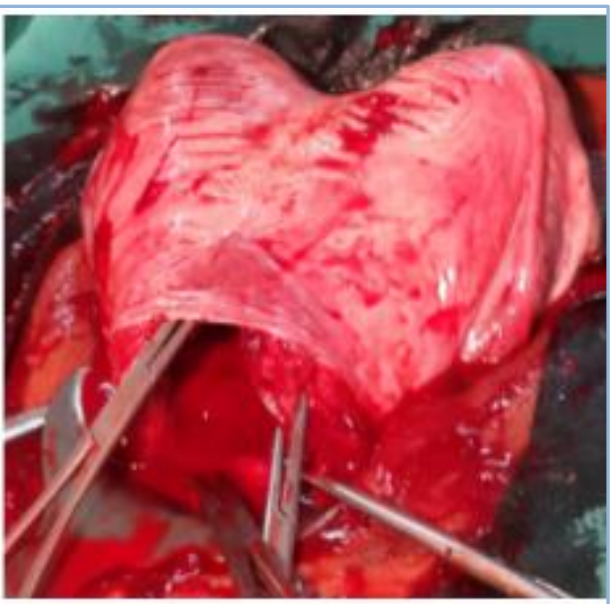

Allis applied to vertical incision Which is extended to right horn

DISCUSSION: Fetal head entrapment is the most dread full complication associated with vaginal breech delivery, to overcome entrapment an obstetrician may try one of the following measures.

1. Attempt the duhrssen incision by cutting the cervix at 2, 6 and $10^{\prime}$ o clock position to increase the size of the cervical aperture. ${ }^{2}$

2. Request an anaesthesiologist to provide inhalational anesthesia for uterine relaxation. ${ }^{3}$

3. Perform an emergency caesarean section (abdominal rescue). ${ }^{4}$

Fetal head entrapment during caesarian breech delivery is uncommon. It usually occurs in a premature fetus, when the lower uterine segment is not well formed. As a consequence the lower 
transverse uterine incision is usually too small to deliver the fetus. Some obstetricians advocate a low midline incision for caesarian breech delivery, as the incision can be easily extended when the entrapment occurs. ${ }^{5}$

Uterine anamoly like bicornuate uterus was the cause for entrapment of head in our case, where head was entrapped in one horn of bicornuate uterus which was delivered by extending the uterine incision vertically from the lower segment incision into this horn and head was delivered without any difficulty after extension of the incision. Both vertical and transverse incision was closed in two layers.

Apart from anomaly of uterus the other rare cause which has to be kept in mind is entrapment caused by abnormal contraction (Contracture) between well-formed upper and lower uterine segment.

This abnormal hypertonic uterine contraction can be released by using intravenous betamimetic drugs or nitroglycerine. ${ }^{6}$ Nitroglycerine (NTG) is an interesting tocolytic agent during caesarian section because it is easy to apply, has quick onset of action and is safe for both fetus and mother. NTG is a potent smooth muscle relaxant and its use in various obstetric emergency conditions is well documented. ${ }^{7}$ NTG can facilitate extraction of an entrapped head during caesarian breech delivery, however it might not be applicable for extraction of the entrapped fetal head during vaginal breech delivery. ${ }^{8}$

CONCLUSION: Although cesarean breech delivery can reduce the complication found in vaginal breech delivery, it cannot get rid of the complications. Obstetricians have to be skillful with accurate techniques of vaginal breech assistance and breech extraction because such techniques are also appropriate to deliver a baby during cesarean section by using the right technique which can facilitate delivery and avoid injuries to the baby, moreover a ready to use uterine relaxing agent should be available in the operating room in order that it can be promptly used when abnormal uterine contraction causing fetal entrapment and prevent unnecessary incisions like inverted $\mathrm{T}$ or low midline "classical incision" in a women who needs further pregnancy, as this incisions have its own complications in future pregnancies.

\section{REFERENCES:}

1. Committee on obstetric practice. ACOG committee opinion: no, 265, dec 2001.mode of term single breech delivery. obstet gynaecol 2001.98: 1189-90.

2. Cunningham FG, et al. representation and delivery. In: Williams obstetrics, 22 edition. Newyork: McGraw hill, 2005, 565-86.

3. YooKY, Lee JC, Yoon MH, Sin MH, Kim SJ, Kim YH, et al. the effects of volatile anstheyics on spontaneous contractalilty of isolated human pregnant uterine muscle: a comparison among sevoflurane, desflurane, isoflurane and halothane. anasth analog 2006, 103: 44327.

4. Iffy L, Apuzzio JJ, Cohen-addad N, Zwolska-Demozuk B, Frncis-Lane M, Olenzak J. Abdominal rescue after entrapment of the after coming head. Am J Obstat Gynecol 1986: 154.623-4.

5. Schutterman EB. Grimes DA. Comparative safety of the low transverse versus the low vertical incision for cesarean delivery of breech infants. Obstet Gynecol 1983; 61: 593-7.

6. Ezra Y, Wade C.Rolbin SH, Farine D. Uterine relaxation with epidural anaesthesia. J Reprod Med 2002; 47: 555-8. 


\section{CASE REPORT}

7. Dufour P, Vinatier D, Puech F. The use of intravenous NGC for cervico-uterine relaxation: a review of the literature. Arch gynaecol Obstet 1997, 261: 1-7.

8. Rolbin SH, Hew EM, Bernstein A. Uterine relaxation can be lifesaving. Can. J. Anaesth.1991; 38: 939-940.

\section{AUTHORS:}

1. Vijayalakshmi B.

2. Amulya M. N.

\section{PARTICULARS OF CONTRIBUTORS:}

1. Associate Professor, Department of Obstetrics and Gynaecology, Vijayanagar Institute of Medical Sciences, Bellary, Karnataka.

2. Junior Resident, Department of Obstetrics and Gynaecology, Vijayanagar Institute of Medical Sciences, Bellary, Karnataka.

FINANCIAL OR OTHER

NAME ADDRESS EMAIL ID OF THE CORRESPONDING AUTHOR:

Dr. Vijayalakshmi. B,

H. No. 10/2, Ward no 19,

Behind Govt. School,

Patel Nagar, Ballari.

E-mail: vijaya.b.yadav72@gmail.com

Date of Submission: 02/07/2015.

Date of Peer Review: 03/07/2015.

Date of Acceptance: 23/07/2015.

Date of Publishing: 30/07/2015. 